CP, 2017, Vol.6 - No11, pp. 129/153 ISSN 2014-6752. Girona (Catalunya). Universitat de Girona. DURÁN MANSO, VALERIANO: La ruptura del modelo de masculinidad en el Hollywood clásico: los personajes de Tennessee Williams y de William Inge. Recibido: 9/12/2016 - Aceptado: $3 / 7 / 2017$

\title{
La ruptura del modelo de masculinidad en el Hollywood clásico: los personajes de Tennessee Williams y de William Inge*
}

\section{The breakdown of the model of masculinity in the classic Hollywood: the characters of Tennessee Williams and William Inge}

\author{
AUTOR: \\ Valeriano Durán Manso \\ Doctor Profesor Sustituto Interino \\ http://orcid.org/0000-0001-9188-6166 valeriano.duran@uca.es \\ Departamento de Marketing y Comunicación. Facultad de Ciencias Sociales y de la Comunicación. \\ Universidad de Cádiz. España. Avenida de la Universidad s/n, 11405 Jerez de la Frontera (Cádiz). España.
}

*Parte de esta investigación procede de la tesis doctoral realizada por la autoría de este artículo "La producción dramática de Tennessee Williams en el cine: aproximación al estudio de personajes", defendida en el Departamento de Comunicación Audiovisual y Publicidad de la Universidad de Sevilla el 4 de marzo de 2014.

\section{RESUMEN}

La construcción de los personajes ocupa un relevante papel en la obra literaria de los dramaturgos norteamericanos Tennessee Williams y William Inge. Este aspecto tiene una presencia determinante en el ámbito cinematográfico debido a que la mayoría de sus textos se llevaron a la gran pantalla en las décadas de los cincuenta y sesenta; una etapa decisiva en Hollywood. Sus seres de ficción están marcados por un rotundo aspecto físico y una profunda complejidad psicológica, y esta combinación adquiere fuerza en los masculinos, quienes participaron en la ruptura con el modelo de masculinidad hegemónico del cine americano clásico. Con los objetivos de poner en valor la obra fílmica de ambos escritores, reflexionar sobre el impacto de sus personajes en el cine, y realizar una aproximación a la representación de la masculinidad en sus principales películas, se intenta reflejar cómo sus protagonistas representaron un modelo inédito, más sensible y sexualizado. En este sentido, los personajes masculinos que se analizan son los principales de Un tranvía llamado deseo (1951),

\section{ABSTRACT}

Construction of characters has a relevant role in the literary work of the American playwrights Tennessee Williams and William Inge. This aspect has a decisive presence in the film industry because the majority of their texts were adapted to big screen in the fifties and sixties; a decisive stage in Hollywood. Its characters are marked by a resounding physical aspect and a deep psychological complexity, and this combination gain relevance in the male, who participated in the breakdown with the model of hegemonic masculinity of classic American cinema. With the objectives of put in value the film work of both writers, to reflect on the impact of the characters in the film and to make an approach to the representation of masculinity in its main movies, this paper tries to reflect how its main characters represented an unprecedented model, more sensitive and become sexualised. In this sense, the male characters that are analyzed are the main of A Streetcar Named Desire (1951), Picnic (1955), Cat on a Hot Tin Roof 
Picnic (1955), La gata sobre el tejado de zinc (1958) y Esplendor en la hierba (1961). Desde estas consideraciones, este trabajo pretende reflexionar sobre cómo los personajes masculinos de las adaptaciones cinematográficas de Tennessee Williams y de William Inge influyeron en el nuevo modelo de masculinidad que se asentó en Hollywood a partir de los años cincuenta.

Palabras clave: masculinidad, Hollywood, cine clásico, personaje, Tennessee Williams, William Inge
(1958) and Splendor in the Grass (1961). From these considerations, this work aims to reflect on how male characters of the film adaptations of Tennessee Williams and William Inge influenced the new model of masculinity that settled in Hollywood from the fifties.

\section{INTRODUCCIÓN}

La obra de los dramaturgos norteamericanos Tennessee Williams (Columbus, Mississippi, 1911-Nueva York, 1983) y William Inge (Kansas, 1913-Hollywood, 1973) está estrechamente vinculada al cine, en concreto, a uno de los periodos más prolíficos de la historia del cine universal. Aunque poseían personalidades muy acusadas, ambos coincidían en su apuesta por crear universos de gran dramatismo mediante estructuras familiares muy complejas; seres de ficción marcados por cuestiones de índole personal, psicológica o sexual; y entornos sociales conservadores y herméticos, en la mayoría de los casos. Además, los dos ambientaron sus principales textos en sus zonas de origen, lo que puso de manifiesto el estrecho vínculo existente entre sus propias experiencias y las de sus personajes en ambos espacios. El éxito que sus obras obtuvieron en los escenarios de Broadway cuando fueron estrenadas, en las décadas de los cuarenta y cincuenta, constituyó el principal trampolín para su rápido traslado a Hollywood, en una época de ruptura, transición y cambio donde la industria fílmica estaba obligada a seguir las directrices censoras que dictaba el Código Hays (Black, 1998; Barton Palmer, 1997). El marco cinematográfico posterior a la II Guerra Mundial estuvo determinado por la crisis del sistema de estudios, el auge de la televisión y la caza de brujas del senador McCarthy (Tasker, 1998), y este panorama propició una serie de cambios definitivos en el cine clásico (Barton Palmer y Bray, 2009). Este modelo narrativo, que se había configurado en la etapa muda, evolucionó a partir de los años cincuenta con el tratamiento de temas más profundos y la construcción de unos personajes más complejos en las películas. En esta línea, los filmes basados en los dramas de Williams y de Inge contribuyeron al nuevo camino que inició Hollywood.

Las principales adaptaciones cinematográficas de los dramas más célebres de estos dramaturgos se filmaron en estos años, y entre ellas destacan: Un tranvía llamado deseo (A Streetcar Named Desire, Elia Kazan, 1951), Picnic (Picnic, Joshua Logan, 1955), La gata sobre el tejado de zinc (Cat on a Hot Tin Roof, Richard Brooks, 1958) y Esplendor en la hierba (Splendor in the Grass, Elia Kazan, 1961). Estos títulos, que se insertan en el melodrama clásico e indican una evolución con respecto al estilo tradicional del género, fueron decisivos en el camino de 
Hollywood hacia la libertad temática. Este cambio fue posible, en buena medida, debido a la apuesta por abordar en los filmes aspectos de tipo generacional, existencial y sexual, y a la incorporación de unos seres de ficción más complejos, diversos y con multitud de aristas. Esta muestra, que es la que centra el presente estudio, cuenta con cuatro protagonistas masculinos que marcaron la fractura con el tipo de masculinidad imperante en el cine clásico: Stanley Kowalski, Hal Carter, Brick Pollit y Bud Stamper, respectivamente. El aspecto físico de estos personajes, el tratamiento de su imagen -a nivel fílmico y publicitario-, y su carácter, actitud o sexualidad, caracterizaron la apuesta por un nuevo tipo de seres de ficción, e incluso influyeron en otros posteriores hasta la actualidad. De esta manera, en apenas diez años el impactante prototipo de masculinidad propuesto en Un tranvía llamado deseo se presentó de forma normalizada ante los espectadores de Esplendor en la hierba.

El patrón de masculinidad dominante en el Hollywood clásico contaba con unas directrices muy marcadas en lo referente a la apariencia, la psicología, la sociología, la sexualidad, o las acciones de los seres de ficción. Se trataba de unos personajes que aunque fueran atractivos a nivel físico, su belleza no solía ser destacada, y que, además, contaban con un universo interno que no era del todo mostrado en la gran pantalla. Sin duda, la visión heteronormativa de la industria cinematográfica determinó el papel que los seres de ficción femeninos ocupaban en las películas, pero, también, la construcción de la masculinidad. Además, este enfoque estuvo fomentado por el Código Hays -cuyas estrictas y conservadoras normas establecían qué debía aparecer en pantalla y qué no-, y por organizaciones influyentes como la Legión Católica de la Decencia. De esta manera, la hegemonía patriarcal imperante en Hollywood impuso en los años treinta un prototipo de masculinidad eminentemente heterosexual y tradicional, que apartó, ocultó e invisibilizó a los personajes homosexuales "encerrándoles en una heterosexualidad entendida como la única sexualidad posible puesto que lo "otro" quedaba, por lo tanto, en el lado de la enfermedad, la perversión" (Zurián Hernández, Martínez Ávila y Gómez Prada, 2015: 56). La masculinidad hegemónica se basó "en la autosuficiencia prestigiosa, la belicosidad heroica, el respeto al valor de la jerarquía, la superioridad sobre las mujeres y sobre los varones menos masculinos y la diferenciación con ellos" (Guarinos, 2013: 13), y así lo reflejó la pantalla. El cine clásico no sólo apostó por una única forma de masculinidad en detrimento de todas las demás posibles, sino que tampoco indagó en los aspectos más profundos de la heterosexualidad con el fin de mostrar a unos protagonistas masculinos más complejos. Por este motivo, se puede afirmar que hasta los años cincuenta no aparecieron por primera vez en el cine protagonistas masculinos de gran atractivo físico, profunda psicología y sexualidades diversas; eso sí, de forma sutil por cuestiones de censura.

Los estudios sobre la masculinidad en el área de comunicación audiovisual -especialmente en cine y en televisión-, son relativamente recientes en España. Sin embargo, se antojan oportunos para poder investigar la construcción de los personajes, como sucede en el presente caso, pues permiten conocer también su universo, el momento histórico y social en el que aparecieron, la forma en que se relacionan, o cómo evolucionaron. Así, en línea con los planteamientos de Seger (2000) sobre la naturaleza psicológica de los personajes de ficción, tanto literaria como audiovisual, se puede destacar lo siguiente:

Un personaje no existe por sí solo, es decir, aislado, sino que aparece siempre en un contexto, con unas influencias culturales según su origen étnico, social, religioso o educativo, en un lugar y un período histórico y con una profesión definida o, en caso con- 
trario, carente de ella. Todo esto son rasgos que determinarán su forma de hablar, su modo de vestir, su modo de actuar y de pensar; es decir, que conformarán su psicología (Galán Fajardo, 2007).

Con estas premisas, se ha recurrido a investigaciones de varios autores sobre la masculinidad en la ficción audiovisual (Zurián Hernández, 2015 y 2014; Guarinos, 2013; Connelly, 2004; y Badinter, 1993); el análisis del personaje audiovisual (Galán Fajardo, 2007; Casetti y Di Chio, 2007; Díez Puertas, 2006; y Seger, 2000); la historia del cine americano (Barton Palmer y Bray, 2009; Tasker, 1998; y Black, 1998); y la producción dramática y fílmica de Williams (Durán Manso, 2016; Williams, 2008; Antón-Pacheco, 2005; Cuevas, 2000; Philips, 1980; y Steen, 1969), y de Inge (Smith-Howard y Heintzelman, 2005; y Kazan, 1990); entre otros. Conforme a estos planteamientos, se ha intentado realizar una aproximación a las citadas adaptaciones de estos dramaturgos, y, en concreto, a sus personajes masculinos protagonistas, por presentar un tipo de masculinidad inédita en el cine clásico, que supuso la ruptura con los cánones existentes y marcó el nuevo rumbo de la industria de Hollywood.

\section{OBJETIVOS}

El objetivo general de este estudio es poner de manifiesto y reflexionar sobre cómo los personajes masculinos de las adaptaciones fílmicas de Tennessee Williams y de William Inge contribuyeron al asentamiento de un nuevo modelo de masculinidad en el cine clásico de Hollywood a partir de la década de los cincuenta. Así, se pretende establecer una relación entre la aparición de estos seres de ficción y el paulatino derrocamiento del patrón imperante desde los treinta. Además, se establecen los siguientes objetivos específicos:

1. Definir el modelo de masculinidad hegemónico del cine clásico hasta la crisis del sistema de estudios de finales de los años cuarenta.

2. Poner en valor la obra fílmica de Williams y de Inge en un periodo de transición en Hollywood, como fueron los años cincuenta y sesenta.

3. Destacar el impacto de sus personajes masculinos en la gran pantalla y de los actores que los interpretaron, en su mayoría nuevos talentos.

4. Realizar una aproximación a la representación de la masculinidad en los protagonistas de las principales películas de estos dramaturgos.

\section{METODOLOGÍA}

Esta investigación es de carácter cualitativo-descriptivo. En primer término, se ha realizado un estudio literario y fílmico de las obras planteadas, pues "para poder analizar los modelos y personajes representados en los distintos medios audiovisuales es necesario comprender, en primer lugar, cuál es el fundamento básico en su construcción" (Galán-Fajardo, 2007). Este corpus está compuesto por las adaptaciones cinematográficas de los textos de Tennessee Williams y de William Inge Un tranvía llamado deseo, Picnic, La gata sobre el tejado de zinc y Esplendor en la hierba, y se centra en los rasgos físicos y psicológicos que componen el modelo de masculinidad al que pertenecen sus protagonistas: Stanley Kowalski, Hal Carter, Brick Pollit y Bud Stamper, respectivamente. En este sentido, resultan muy pertinentes las indicaciones realizadas por estos autores en las obras de teatro sobre los seres de ficción, para cotejar después su plasmación en la pantalla. En la mayoría de estas películas, la imagen de los personajes resulta más potente a nivel sexual que en los textos, a pesar de la habilidad descriptiva de ambos autores. Esto se debe al empleo de diversos recursos narrativos y técnicos propios 
del lenguaje audiovisual para reforzar la sensualidad de los protagonistas, lo que explica el impacto que ocasionaron en el espectador del momento. Así, las formas de representación de la literatura y el cine resultan fundamentales en estas adaptaciones:

La construcción del personaje debe observarse bajo un prisma distinto, orientado a la exteriorización de los rasgos internos y a la acción, herramientas diferentes al proceso de lectura de una novela, donde la comprensión del personaje se produce desde dentro, desde sus propios pensamientos, mientras que en el cine estos deben expresarse a través de distintos recursos como la voz en off, la acción o el monólogo (Galán Fajardo, 2007).

Por otra parte, se ha recurrido a diversas investigaciones sobre la obra literaria y cinematográfica de estos dramaturgos, así como a publicaciones de carácter divulgativo, como libros de entrevistas y de correspondencias donde ambos reflexionan sobre su producción con algunos de los participantes del proceso de adaptación de la misma. Sobre este aspecto, la perspectiva de Elia Kazan -director de Un tranvía llamado deseo y de Esplendor en la hierba-, resulta muy acertada porque se encargó también del montaje de la primera en Broadway -constituyendo así su primer acercamiento al universo de Williams-, y mantuvo una estrecha relación con ambos escritores. Es necesario tener en cuenta que las adaptaciones utilizadas son las primeras que se realizaron en Hollywood sobre las obras originales, y que aunque todas han contado posteriormente con versiones televisivas de éxito en Estados Unidos y con numerosos montajes teatrales en distintos países -incluso en la actualidad-, ninguna ha vuelto a ser llevada al cine. Se trata de películas que tuvieron una relevante repercusión en los años cincuenta y sesenta por tres cuestiones: aparecer durante la crisis de carácter estructural, político y económico que atravesaba Hollywood; apostar por temas prohibidos por el Código Hays; y presentar a unos protagonistas masculinos inéditos por su gran atractivo físico y complejidad interna.

Los melodramas elegidos corresponden a dos de las adaptaciones fílmicas más relevantes y representativas de Williams -Un tranvía llamado deseo y La gata sobre el tejado de zinc-, una de las más aclamadas de Inge -Picnic-, y un exitoso guión que este último escribió directamente para el cine -Esplendor en la hierba-. Las tres primeras derivan de sus respectivas obras homónimas, se estrenaron de forma alternada en función de sus presentaciones en Broadway, y consiguieron el Premio Pulitzer para sus autores. Asimismo, todas obtuvieron un importante éxito de público y de crítica, y fueron distinguidas con diversas nominaciones y premios Oscar, entre otros célebres galardones; lo que indica su calidad audiovisual y su carácter comercial. Una de sus principales innovaciones se concretó en el modelo de masculinidad de sus protagonistas, que combinaba la fuerza de la imagen física -y una estética que la realzaba-, con la fragilidad de sus controvertidas, e incluso atormentadas, personalidades. No obstante, los cuatro personajes presentan matices diferentes en función de la historia que protagonizan y su desarrollo dentro de ella, y, en este sentido, se puede percibir una gradación y una cierta evolución desde la aparición de Stanley Kowalski a la de Bud Stamper. Así, la rudeza sexual del primero -sin duda, el más impactante de todos-, se muestra más suavizada en Hal Carter, y, especialmente, en Brick Pollit, cuya belleza es bastante más estilizada y su universo mucho más débil. En el último caso, este modelo de masculinidad resulta menos llamativo para el público con respecto a los anteriores porque los espectadores ya lo habían asimilado y, en buena parte, aceptado.

En este trabajo se plantea un análisis de personajes como persona y como rol que atiende, en 
el primer caso, a rasgos relativos a la iconografía, la psicología, la sociología o la sexualidad de cada uno de ellos, y, en el segundo caso, a la función que ocupan en el relato. Por ello, se ha aplicado la plantilla de análisis de personajes creada en 2009 por el Equipo de investigación en Análisis de Medios, Imágenes y Relatos Audiovisuales (ADMIRA), del Departamento de Comunicación Audiovisual y Publicidad de la Universidad de Sevilla, basada en los planteamientos de Francesco Casetti y Federico di Chio. Esta herramienta cualitativa -heredera a su vez de los trabajos de otros autores relevantes en la narrativa como Algirdas Julius Greimas o Vladimir Propp-, permite conocer elementos clave de los seres de ficción, como la edad, la apariencia, la manera de hablar, el carácter, la forma de relacionarse con los demás, su pensamiento, sus sentimientos, su evolución psicológica, el nivel social, económico y cultural que tienen, su sexualidad, o las motivaciones de las acciones que realizan y el papel que desempeñan en la narración. A este respecto, "las tramas narradas son siempre, tramas 'de alguien', acontecimientos y acciones relativos a quien, como hemos visto, tiene un nombre, una importancia, una incidencia y goza de una atención particular: en una palabra, un 'personaje'"' (Casetti y Di Chio, 2007: 159). Asimismo, "componer un personaje es definir su personalidad, su identidad: su carácter" (Diez Puertas, 2006: 171). Los ítems de esta plantilla se basan en aspectos que humanizan a los personajes, les otorga una condición universal, y destacan su construcción coherente como seres sacados de la vida real, que funcionan y evolucionan de forma creíble en la historia. Además, al pertenecer estos filmes al melodrama -uno de los géneros más populares por su carácter emocional-, se intenta fomentar el proceso de identificación entre el público y los protagonistas. Sin duda, resulta necesario destacar la importancia del análisis del texto audiovisual, "pero sin olvidarnos que puede contener, y de facto contiene, muchas implicaciones en la representación y en la construcción de identidades" (Zurián Hernández y Herrero Jiménez, 2014: 18).

\section{RESULTADOS Y DISCUSIÓN}

\subsection{El modelo de masculinidad en el cine clásico}

El cine americano clásico se instaló como modelo narrativo en la década de los diez, pero tuvo un mayor desarrollo en el sonoro. Así, el periodo comprendido entre 1927 -año en el que se estrenó la primera película hablada, El cantor de jazz (The Jazz Singer, Alan Crosland)-, y 1972 -fecha en la que comenzó el cine posmoderno-, fue el más decisivo en el asentamiento de Hollywood como primera industria cinematográfica mundial. Aunque las carreras de buena parte del star system se truncaron por la compleja transición al sonoro, el modelo de masculinidad imperante en los años silentes, sobre todo en los veinte, destacó con actores como Douglas Fairbanks Jr. y, especialmente, Rodolfo Valentino. Ambos representaban a un hombre atractivo, viril, seductor y pasional, que en el segundo caso resultaba exótico a los espectadores por su origen italiano. Su imagen aparecía potenciada, e incluso sexualizada, en las películas, pero esta exitosa tendencia fue eliminada poco después con la implantación del Código Hays en 1934. Con los objetivos de proteger la moral del público y evitar que la sociedad se corrompiera, en la nueva década se produjo un giro conservador que tuvo una gran repercusión en los temas y tipos de personajes que se trataban en los filmes (Durán Manso, 2016). Esto afectó notablemente a la imagen de los seres de ficción, pues se desterró el modelo vigente.

Además del código de censura, y de organizaciones afines como la Legión Católica de la Decencia (Black, 1998), el ámbito cinematográfico de los treinta también estuvo marcado por la 
política social del New Deal. El patrón de masculinidad asimiló esta realidad mediante unos personajes principales en los que primó un hombre de aspecto sencillo, carácter íntegro, actitud esperanzada y heterosexual, entre otros muchos rasgos. Con ello, se pretendía buscar la identificación con el norteamericano medio, cuya única forma de ocio posible era el cine debido a las duras consecuencias del Crack de 1929. No obstante, predominaron dos modelos que se mantuvieron hasta la década siguiente:

1. El hombre del New Deal. Comparte la mayoría de los rasgos citados y aparece en películas de diversos géneros. Suele tener un arraigado sentido de la familia, valores y un fuerte compromiso con la situación de crisis que atraviesa Estados Unidos. Además, pertenece a una clase social media o baja y lucha por salir adelante. Algunos actores que lo reflejaron con fidelidad fueron Spencer Tracy, Henry Fonda o Gary Cooper, en filmes como Forja de hombres (Boys Town, Norman Taurog, 1938), Las uvas de la ira (The Wrapes of Wrath, John Ford, 1940) -basada en la obra homónima de John Steinbeck-, o Juan Nadie (Meet John Doe, Frank Capra, 1941), respectivamente.

2. El gentleman. Este prototipo destacó en el melodrama y en la alta comedia, géneros destinados a la evasión de una sociedad debilitada por la Depresión. Lo representan personajes de aspecto varonil, que portan un elegante vestuario y poseen un elevado estatus. Asimismo, encarnan los sueños de los espectadores y representan el ideal de masculinidad. Algunos de sus mejores exponentes fueron Clark Gable (Connelly, 2004), Cary Grant, o Robert Taylor, en Encadenada (Chained, Clarence Brown, 1934), Vivir para gozar (Holiday, George Cukor, 1938), y Margarita Gautier (Camille, George Cukor, 1937), en este orden. Henry Fonda y Gary Cooper también lo interpretaron.

Durante los cuarenta, la situación económica fue mejorando y el primer modelo dejó de ocupar un lugar destacado. A su vez, al segundo se incorporaron, entre otros, actores como James Stewart, en la comedia Historias de Filadelfia (The Philadelphia Story, George Cukor, 1940), y Tyrone Power, en el melodrama El filo de la navaja (The Razor's Edge, Edmund Goulding, 1946). Sin embargo, en estos años surgió un tipo de personaje masculino ubicado en entornos urbanos y próximo al ciudadano de a pie, en lo que respecta a la estética y al ámbito profesional -más diverso y competitivo-; es decir, muy vinculado al american way of life. Este patrón, que se puede denominar hombre actual, se hallaba entre los anteriores y se erigió como el principal de la década, pues, además, todos los intérpretes citados empezaron a encarnarlo. En líneas generales, se puede decir que estas tres posibilidades se enmarcaban en una masculinidad clásica, en la que el atractivo del protagonista no solía resaltarse -a excepción de Taylor y de Power-, y que se manifestaba según estos criterios:

1. Iconográfico. Van afeitados o con bigote, llevan pelo corto y con la raya a un lado, mantienen una postura erguida y caminan firmes. Su aspecto huye de todo lo vinculado con lo femenino o andrógino -como ocurría con Valentino-, y, por ello, su vestuario está compuesto por trajes, corbatas y sombreros, tanto para trabajar como para salir. Aunque pueden aparecer con un atuendo informal, sobre todo en las zonas rurales, casi nunca salen con camisetas y vaqueros al estar asociados al mundo obrero. Además, la ropa suele ser muy holgada porque existe una ausencia de ensalzar la figura masculina.

2. Psicológico. Se trata de seres de ficción emocionalmente estables, que actúan y se relacionan según los cánones del heteropatriarcado, es decir, de forma homosocial, aunque suelen establecer un vínculo protector con las mujeres. Normalmente, ofrecen una imagen segura ante los demás y no se dejan llevar por los sentimientos. 
3. Sociológico. Este modelo de masculinidad se da en personajes de todos los niveles sociales, económicos y culturales, pues se trata de un patrón tradicional hegemónico en los distintos géneros narrativos.

4. Sexual. Se destierra la idea de cualquier otra sexualidad que no sea la heterosexual, y esto corresponde a "la tradición del silencio auto-impuesto, del acallamiento de la voz homosexual que sin embargo deja sus huellas en el erotismo sublimado de la épica o el melodrama de Hollywood" (Martínez-Expósito, 2009: 29).

Dadas estas características, el modelo de masculinidad imperante en el cine clásico correspondía al de un "hombre homosocial, falocéntrico, heterosexual, dominante, en definitiva, el modelo de hombre patriarcal, como se conoce desde la Teoría feminista" (Guarinos, 2013: 9). Asimismo, el atractivo físico residía casi exclusivamente en los personajes femeninos, a modo de reclamo para los masculinos y los propios espectadores. Esto pone de manifiesto que en las primeras décadas de este periodo, los protagonistas fueron construidos según estos aspectos para fomentar y perpetuar el esquema patriarcal. Este modelo siguió vigente hasta el cine posmoderno, pero empezó a perder su primacía en los cincuenta por la irrupción de nuevas masculinidades.

\subsection{Las adaptaciones de Tennessee Williams y de William Inge: impacto y repercusión en Hollywood}

En la década de los cuarenta, la escena neoyorquina gozaba de una mayor libertad que Hollywood porque carecía del control de las estructuras censoras (Barton Palmer, 1997). Esto posibilitaba el estreno de dramas con temáticas que eran impensables en la gran pantalla y con unos seres de ficción de gran complejidad psicológica. Así, el camino iniciado en los años veinte por Eugene O'Neill -considerado "el padre del teatro estadounidense" (Antón-Pacheco, 2005: 25)-, permitió la presencia de nuevos dramaturgos en los cuarenta, como Tennessee Williams, quien en 1944 estrenó su primera gran obra, la memory play El zoo de cristal. Esta pieza revolucionó Broadway por su carácter íntimo, sus atormentados personajes y el desencanto que transmite. Precisamente, fue también el punto de unión entre Williams y William Inge, quien en aquellos años trabajaba en un periódico de Saint Louis, como recuerda el primero:

I met him in S. Louis. I came back there during the run of Menagerie in Chicago, and he interviewed me for a paper called the St. Louis Star-Times. He was the drama and music critic for it. He entertained me quite a bit the week I was there. We became friends (Devlin, 1986).

A raíz de esta entrevista -realizada con motivo de un artículo que Inge escribió sobre la citada obra-, ambos entablaron una gran amistad que perduró hasta la muerte del segundo. Prueba de ello, es que Inge asistió con Williams al estreno de El zoo de cristal en Chicago, un evento que marcó su dramaturgia, como confesó años después: "the play was a great experience for me, too, in that it enabled me for the first time to see the true dynamics between life and art", una declaración que completó con estas palabras: "Tennessee had told me just enough of his life that I could see through the symbolism of the play and see how he had arrived at this work. How he had achieved it" (Steen, 1969: 98). Sin embargo, la obra de Williams que conquistó Hollywood fue Un tranvía llamado deseo. Estrenada en 1947, consiguió el New York Drama Critic's Circle Award -al igual que El zoo de cristal-, el Donaldson y el Pulitzer -el primero de los dos que obtuvo el escritor-, al abordar "en un ámbito tan reducido como un angosto apartamento 
de Nueva Orleans, temas como la ninfomanía, el adulterio y la violación, bajo el denominador común del deseo" (Durán Manso, 2016: 59-60). Por su parte, el primer drama de Inge fue Farther Off from Heaven, que escribió después de la experiencia de Chicago. El autor se lo remitió a Williams, y como le gustó, éste lo envió a su agente, Audrey Wood, y después a Margo Jones, quien lo produjo en 1947 en Dallas. El éxito que obtuvo se afianzó de inmediato con su siguiente obra, Vuelve, pequeña Sheba, que fue estrenada en 1950 en Broadway y llevada al cine. Sin duda, "Williams was instrumental in launching Inge's career. Inge never forgot this and thanked Williams for his support and encouragement by dedicating The Dark at the Top of the Stairs (1957), his last work, to Williams" (Smith-Howard \& Heintzelman, 2005: 352).

La excelente acogida que tuvieron estas obras en Broadway despertó el interés por llevarlas al cine, a pesar de la crítica situación que atravesaba la industria, pues el sistema de estudios fue declarado un monopolio ilegal, la televisión experimentó una rápida expansión y empezaron las persecuciones de la Caza de Brujas del senador McCarthy (Tasker, 1998; Barton Palmer, 1997). Para paliar la pérdida de espectadores, se fomentaron dos estilos mediante un cine colosal en formatos panorámicos -que favoreció el desarrollo de títulos bíblicos y los denominados peplums-, y otro de carácter intimista cuya fuerza residía en los temas y personajes. Las películas de Williams se instalaron en el segundo grupo, y después lo hicieron las de Inge, dominando ambos una tendencia a la que Hollywood sumó rápidamente obras de Arthur Miller o Robert Anderson. A diferencia del primero, que acogía producciones de gran presupuesto, contaba con una realización sencilla, hablaba de forma directa al espectador y abarcaba una gran variedad temática. Los atrevidos aspectos de estos autores suponían una ruptura con el cine moralista que defendía el Código Hays, pero resultaban atractivos para el público. Esta circunstancia fue aprovechada por diversos productores y cineastas como protesta por la ausencia de libertad temática en Hollywood, y, en este propósito, la producción de Williams y de Inge resultaba bastante oportuna. En la mayoría de los casos, tuvieron que luchar contra la censura para que las adaptaciones fueran fieles a los originales; una operación en la que destacó la habilidad cinematográfica y narrativa de directores como Elia Kazan o Richard Brooks, quienes sugirieron mediante metáforas, diálogos, o planos la carga sexual que no podían mostrar. Por ello, se puede considerar que los estrenos de estos filmes, que se sustentaban sobre temas prohibidos, derrocaron poco a poco un código de censura que impedía al espectador identificarse con los planteamientos que aparecían en la pantalla:

La caída del sistema de estudios y los cambios sociales de estos años se entrecruzaron también para permitir una paulatina transformación de los modos dominantes de hacer cine, como se puede observar en la mayor complejidad de las películas de Kazan, reforzada por la contribución que suponen los nuevos modos interpretativos del Actor's Studio (Cuevas, 1998).

Desde un principio, el Actor's Studio estuvo vinculado a estos escritores, pues la introspección de su formación actoral coincidía con el universo psicológico de ambos. Así, "his characters, in turn, could only be fully realized by a different kind of naturalistic acting capable of representing conflicted, multilayered selves: the so-called 'Method' that had recently come into vogue the founding of the Actor's Studio" (Barton Palmer, 1997: 207). Fundada en Nueva York en 1947 por Cheryl Crawford, Kazan y Robert Lewis, se convirtió en una de las principales escuelas de interpretación del mundo gracias a sus enseñanzas basadas en el método de Konstantin Stanislavski. Este teórico ruso instauró un nuevo estilo escénico y desarrolló una fórmula de 
actuación basada en la relajación, la concentración y la imaginación, para interiorizar las características del personaje. En la construcción de los estados emocionales, cada actor debía tener la capacidad de crear un estímulo interior que lo aproximara al ser de ficción, lo que se llamó el 'sí mágico', y emplear la memoria emotiva, es decir, recurrir a los recuerdos para encontrar una situación análoga a la que éste vive (Stanislavski, 2010). Este modelo tuvo mucha influencia en el teatro moderno, sobre todo, en la renovación de la puesta en escena realista, y posibilitó que los intérpretes sintieran y proyectaran emociones reales a los personajes. Entre sus muros se formaron actores que trabajarían en obras y en filmes de Williams y de Inge, como Marlon Brando, Karl Malden, Carroll Baker, Marilyn Monroe, Paul Newman, Geraldine Page o Warren Beatty, entre otros (Frome, 2001).

En poco tiempo, Williams e Inge se convirtieron en dos de los dramaturgos más adaptados en la historia de Hollywood, y sus películas marcaron la evolución temática y estilística de esta industria desde la década de los cincuenta a la de los setenta. Las películas realizadas sobre la obra literaria del primero fueron El zoo de cristal (The Glass Menagerie, Irving Rapper, 1950), Un tranvía llamado deseo, La rosa tatuada (The Rose Tattoo, Daniel Mann, 1955), Baby Doll (Baby Doll, Elia Kazan, 1956), La gata sobre el tejado de zinc, De repente... el último verano (Suddenly, Last Summer, Joseph L. Mankiewicz, 1959), Piel de serpiente (The Fugitive Kind, Sidney Lumet, 1960), Verano y humo (Summer and Smoke, Peter Glenville, 1961), La primavera romana de la señora Stone (The Roman Spring of Mrs, Stone, José Quintero, 1961), Dulce pájaro de juventud (Sweet Bird of Youth, Richard Brooks, 1962), Reajuste matrimonial (Period of Adjustment, George Roy Hill, 1962), La noche de la Iguana (The Night of the Iguana, John Huston, 1964), Propiedad condenada (This Property Is Condemned, Sydney Pollack, 1966), La mujer maldita (Boom!, Joseph Losey, 1968) y, por último, Last of the Mobile Hot Shots (1970). Estos quince filmes se completan con las adaptaciones cinematográficas de Inge Vuelve, pequeña Sheba (Come Back, Little Sheba, Daniel Mann, 1952), Picnic, Bus Stop (Bus Stop, Joshua Logan, 1956), En la escalera oscura (The Dark at the Top of Stairs, Delbert Mann, 1960) y Rosas perdidas (The Stripper, Franklin J. Schaffner, 1963); y los guiones de Esplendor en la hierba, Su propio infierno (All Fall Down, John Frankenheimer, 1962) y Brazos de terciopelo (Bus Riley's Back in Town, Harvey Hart, 1965) -que firmó como Walter Gage-. Asimismo, la mayoría de estos títulos han contado con diversas versiones televisivas.

Ambos escritores destacaron por tres aspectos que renovaron el panorama de Hollywood: los temas, los personajes y los espacios. En primer lugar, en sus obras suelen tratar los conflictos generacionales, la locura, el alcoholismo, la soledad, la ninfomanía, la homosexualidad, o la represión sexual, entre otros, de manera que se puede afirmar que el sexo y el miedo son los principales ejes en los que coinciden. Asimismo, sus protagonistas destacan por poseer una imagen atractiva, incluso los perversos -algo innovador para el momento-, y una gran profundidad psicológica que los aproximaba a la realidad personal, familiar y emocional de los espectadores. En este sentido, la tipología de seres de ficción de Williams, compuesta por damas al límite, jóvenes atormentados, progenitores dominantes, integrados en la vida, y fugitivos y almas a la deriva (Durán Manso, 2011), se puede aplicar también a los de Inge. Además, estos dramaturgos mostraron una clara tendencia por ubicar sus tramas en espacios cerrados que reflejaban su origen teatral, sociedades puritanas, pequeñas ciudades conservadoras ubicadas normalmente en sus estados de procedencia -Mississippi, en el primer caso, y Kansas, en el segundo-, y familias donde el ansia de libertad de los personajes más jóvenes es aniquilada. 
Así, los temas arriesgados y los protagonistas complejos se desarrollaron en unos espacios de carácter hermético y marcado dramatismo.

\subsection{Nueva masculinidad y nuevos talentos}

El desarrollo del potencial iconográfico y de la profundidad psicológica de los personajes masculinos marcó la ruptura con el modelo hegemónico del cine clásico de Hollywood. Aunque esta realidad no fue patente hasta los cincuenta, se percibieron ciertos atisbos de cambio en personajes de películas anteriores, como Charlie Oackley, el complejo protagonista de La sombra de una duda (Shadow of a Doubt, Alfred Hitchcock, 1943). Interpretado por Joseph Cotten, su aspecto correspondía al prototipo de galán de la época, pero esta impecable apariencia era totalmente opuesta a sus acciones, pues era un asesino en serie y casi nadie de su entorno lo sabía. Hasta el momento, los denominados malos solían carecer de belleza física para evitar que resultaran atractivos para el público, pero esta tendencia empezó a cambiar de forma sutil pero progresiva en estos años. Si bien es cierto que Cotten no aparecía en pantalla cometiendo un crimen, y los espectadores percibían su verdadera personalidad a través del suspense, poco después aparecieron intérpretes con un aspecto sexualizado, que, además, exhibían de forma explícita su agresividad. Así se produjo con Stanley Kowalski, el personaje williamsiano que en 1951 provocó la ruptura y se convirtió en uno de los que reflejaron con más exactitud el nuevo modelo de masculinidad. Este estilo se plasma en los siguientes criterios:

1. Iconográfico. Destacan por una patente belleza física, un gesto viril y una complexión atlética que se refuerza en un vestuario compuesto normalmente por camisetas, pantalones vaqueros y cazadoras de cuero. Llevan el pelo corto, van siempre afeitados, suelen ser altos y apuestos, y llaman la atención tanto por su imagen sexualizada -y potenciada por su ajustada indumentaria-, como por presentar un tipo de hombre totalmente opuesto al de sus clásicos progenitores. En contraposición al modelo vigente, existe el propósito de potenciar una imagen masculina joven mediante el físico y el vestuario.

2. Psicológico. Se trata de seres de ficción que ocultan su fragilidad tras una aparente seguridad. Tienen una gran complejidad psicológica que los lleva en numerosos casos a sufrir inestabilidad emocional. Además, son independientes y no suelen responder de forma estricta a los cánones patriarcales, y esto los enfrenta con la figura paterna. Los sentimientos los dominan y las relaciones que mantienen con las mujeres son en buena medida tormentosas y pasionales.

3. Sociológico. Aparecen en sociedades conservadoras y puritanas, y pertenecen a familias de diversa posición, aunque destacan los de clase alta porque representan la nota discordante. Normalmente, proceden de entornos sureños porque la mayoría de los escritores que los desarrollaron, como Williams o Inge, eran oriundos del sur. Por su imagen, la actitud rebelde que manifiestan y su profundidad interna son víctimas de los convencionalismos sociales.

4. Sexual. Aunque la mayoría son personajes heterosexuales, pues la homosexualidad estuvo prohibida por el Código Hays hasta 1961, algunos filmes presentaron a jóvenes homosexuales en este modelo. Debido a su atractivo físico parecían relegados al deseo femenino, pero su drama interior los hacía muy interesantes para encarnar una orientación que en esos años no se podía expresar ni en la calle ni en la pantalla. En este sentido, son homosexuales trágicos.

Existe una estrecha relación entre este tipo de personaje y los actores que lo interpretaron, 
sobre todo los que se formaron en el Actor's Studio. El caso más destacado es el de MarIon Brando, quien sólo tenía veintitrés años cuando se subió al escenario por primera vez para encarnar a Stanley Kowalski, y obtuvo un éxito arrollador tanto en Broadway como en la adaptación cinematográfica de Un tranvía llamado deseo. A pesar de su juventud, realizó una interpretación muy humana del personaje, al que dio la sensibilidad y brutalidad adecuadas para que resultara creíble y el público no lo refutara por sus primarias acciones. Sin embargo, lo que causó furor en los espectadores fue su aspecto, pues la caracterización de Kowalski marcó el nacimiento de un nuevo concepto del atractivo masculino en el cine y, en extensión, en la sociedad americana. Hasta la fecha, los galanes mostraban un cuidado aspecto y unos modales educados, mientras que los perversos eran encarnados por intérpretes poco agraciados. En este caso se produjo una combinación de ambos, ya que la belleza física de Brando era innegable y, por primera vez, un actor con cualidades para ser un perfecto galán daba vida a un ser tan desagradable como Stanley. Además, su aparición en pantalla con una camiseta ajustada y sudada que marcaba su musculatura, con gesto desafiante, aportó una sensualidad sin precedentes en la historia del cine. Esta imagen fue explotada para promocionar el filme, y a pesar de que constituyó una gran provocación para la época, tuvo tal éxito que convirtió a Brando en un icono de masas. Su trabajo sobre las tablas y en el cine resultó muy acertado al conjugar fuerza, descaro, debilidad y temor:

El Stanley Kowalski de Marlon Brando se ha convertido con el paso del tiempo en una de las representaciones más arquetípicas de un intérprete del Actor's Studio. Sus manierismos, sus diálogos mal articulados y su intensidad emocional constituyeron toda una novedad en Hollywood y marcaron un hito en la historia de la interpretación en el cine. Brando sorprendió a todos por la agresividad con la que encarnó al personaje de Kowalski, con una fuerza y una transparencia muy ajenas a las convenciones habituales, habitualmente mucho más medidas en su exteriorización de los sentimientos (Cuevas, 2000: 78-79).

Con este trabajo, el actor inauguró un prototipo de personaje destacado por tener un gran atractivo físico, una actitud ante la vida contraria a las pautas de la sociedad y una profunda sensibilidad. Esta combinación conectó muy bien con el público adolescente, pues reflejaba los problemas que los enfrentaban a sus padres y profesores, quienes encarnaban la opresión de su existencia. En este contexto se gestó la aparición del rebelde, un ser de ficción que tuvo un gran éxito en el cine, fue explotado en los cincuenta por los alumnos del Actor's Studio, y constituyó "una de las principales fuentes de ingresos para la meca del cine, que encontró en ellos un filón inagotable, sobre todo teniendo en cuenta que desde inicios de la década que nos ocupa había empezado a perder espectadores y necesitaba atraerlos" (Ramos Rodríguez, 2007: 195). A pesar de la aportación de Brando, el actor que mejor representó este prototipo fue James Dean en títulos tan significativos de su breve carrera como Rebelde sin causa (Rebel without a Cause, Nicholas Ray, 1955).

Otro de los intérpretes más característicos de esta nueva masculinidad fue Paul Newman. Aunque llevaba poco tiempo dedicado al cine, no tardó en destacar con los difíciles protagonistas de Marcado por el odio (Somebody Up There Likes Me, Robert Wise, 1956) y El zurdo (The Left Hunded Gun, Arthur Penn, 1958), un western donde realizó un retrato psicológico y desmitificador de Billy 'The Kid'. De nuevo, la citada escuela sorprendió con un intérprete versátil y sensible que se convirtió rápidamente en uno de los más adecuados para dar vida 
a los complicados personajes de Williams. Como Brando había abierto el camino a este tipo de héroe, o más bien antihéroe, los productores empezaron a buscar a actores con registros similares con la idea de llevar a la pantalla sus obras. Así, resultó elegido para encarnar a seres de ficción agraciados a nivel físico, pero frágiles y atormentados, que ocultaban sus verdaderas inquietudes por miedo a enfrentarse a sí mismos y a la sociedad que los atrapaba, como reflejó en un personaje esencial de su trayectoria: Brick Pollit, en La gata sobre el tejado de zinc. El propio autor consideraba que Brando y Newman eran dos actores fundamentales en la representación de sus personajes masculinos:

Edwige Feuillère, Anna Magnani y Laurette Taylor han sido las tres máximas intérpretes de mi teatro. En los papeles masculinos destaca Marlon Brando, a quien considero el más grande actor vivo; mayor incluso que Laurence Olivier. Vi a regañadientes El último tango en París, porque me habían dicho que era pornográfica. No lo era, y estimo que Brando ofreció en ella la mejor interpretación que le he visto. Paul Newman también es extraordinario. Le cuesta mucho entrar en un papel, pero cuando por fin lo consigue, es maravilloso (Williams, 2008: 135).

Por su parte, Montgomery Clift, el rebelde más romántico, sensible y humano, era el defensor de un idealismo que sólo respondía a su propia soledad, como plasmó en filmes como De aquí a la eternidad (From Here to Eternity, Fred Zinneman, 1953) o El árbol de la vida (The Raintree County, Edward Dmytryk, 1957). A pesar de que su trabajo como el Dr. Cukrowicz en De repente... el último verano no estuvo muy vinculado a la complejidad psicológica propia de esta masculinidad, destacó por la búsqueda de la verdad en una sociedad interesada por la destrucción del débil, y esta sensibilidad estaba en la línea del nuevo modelo. De esta manera, "the male roles in Williams's plays, reaching a wider audience through various film versions, popularized a different kind of masculinity, offering images of desirable, vulnerable, and yet aggressive maleness that profoundly affected American ideas about gender" (Barton Palmer, 1997: 231). En cuanto a la obra fílmica de William Inge, el actor que mejor encarnó este prototipo por la unión de juventud, atractivo y rebeldía fue Warren Beatty en Esplendor en la hierba como Bud Stamper, pues aunque William Holden exhibía una imagen potente como Hal Carter en Picnic, era más mayor que los anteriores, no se formó con ellos en el Actor's Studio, poseía una actitud vigorosa y aún estaba vinculado a la idea clásica de galán.

Además de estos dramaturgos, en los cincuenta proliferaron las adaptaciones cinematográficas de algunas de las obras de mayor éxito de otros reconocidos escritores norteamericanos contemporáneos. Así sucedió con el aclamado texto de John Steinbeck, Al este del edén (East of Eden, Elia Kazan, 1954), protagonizado por James Dean; o de William Faulkner, El largo y cálido verano (The Long, Hot Summer, Martin Ritt, 1958), que tuvo a Paul Newman como protagonista. Ambas contaban con situaciones oprimidas, mostraban conflictos de tipo sexual y destacaban por la inestabilidad emocional de sus protagonistas masculinos; de manera que compartían universos similares a los de Williams e Inge. Asimismo, también sobresalió la aclamada versión fílmica de la novela An American Tragedy, de Theodore Dreiser, titulada Un lugar en el sol (A place in the Sun, George Stevens, 1951). Aquí, un joven Montgomery Clift cometía un inesperado asesinato para poder escalar a nivel social; sin duda, un suceso que no se correspondía con su imagen atractiva e, incluso, indefensa. 


\subsection{Análisis de personajes \\ 4.4.1. Stanley Kowalski: la imposición de lo salvaje}

La revelación de Un tranvía llamado deseo fue el personaje del rudo y violento Stanley Kowals$\mathrm{ki}$, un ser agresivo que emana una sensualidad profundamente arrebatadora. Con un origen humilde y una precaria educación, el protagonista es un ser primitivo que utiliza la fuerza bruta para imponer su voluntad cuando percibe que su dominio se tambalea. Su unión con Stella DuBois deriva de una atracción meramente física, y este ímpetu será el que utilice para acabar con su cuñada Blanche, una mujer demasiado remilgada para su gusto. Él refleja cómo lo más sórdido consigue aniquilar la delicadeza humana.

El estudio del personaje como persona parte, en primer lugar, de un análisis de tipo iconográfico. Stanley tiene entre 28 y 30 años, posee una belleza viril, y su constitución física atlética le confiere un aspecto musculoso que se completa con un rostro muy agraciado. La imagen sensual que desprende es potenciada con un vestuario compuesto por unos desgastados vaqueros y camisetas ajustadas que realzan su atractivo y acentúan su carácter obrero. Esta vulgar indumentaria creada por la diseñadora Lucinda Ballard -que se inspiró en los trabajadores que cavaban zanjas en las calles de Nueva York-, es la que mejor lo define, incluso cuando lleva encima una cazadora de cuero o el mono de la fábrica. No obstante, en algunas escenas aparece con traje y corbata, y con un pijama de seda. Además del vestuario, su peculiar forma de hablar es otro de los rasgos que lo identifican, pues refleja "la voz del varón de clase trabajadora norteamericano: gutural, burlona y ligeramente atiplada" (Bosworth, 2003: 220). A nivel comunicativo, también destaca por sus frecuentes cambios de humor, como indica que en cuestión de segundos pueda pasar de los gritos al susurro, y del interés más absoluto por una conversación al pasotismo más chulesco. Debido a esta ambivalencia, utiliza un lenguaje repleto de dobles intenciones, sobre todo con Blanche, pero, también, un discurso persuasivo para manipular a Stella. Aunque no experimenta una gran transformación iconográfica, en la escena final, cuando se llevan a Blanche al sanatorio, muestra un aspecto más formal al llevar un pantalón chino gris y una camisa estampada por dentro. Así, su imagen abandona la agresividad de la camiseta y apuesta por la seriedad.

Desde un punto de vista psicológico, Stanley carece de afán de superación, ni vital ni profesional, y es feliz con lo que posee: un trabajo poco cualificado, una vida conyugal satisfactoria, y unos amigos con los que juega a los bolos y al póker cada semana: Mitch, Steve y Pablo. A pesar de este aparente equilibrio, posee un carácter muy fuerte y violento, que no duda en manifestar en cuanto los demás hacen algo con lo que no está de acuerdo, como se ve en la primera escena en la que aparece, en la bolera, donde casi llega a las manos con otro jugador. Esta agresividad va unida a un comportamiento tosco, pues no goza de una buena educación debido a su condición humilde de inmigrante polaco. Asimismo, sus modales son muy vulgares, y prueba de ello es que sonríe y mira de forma desafiante, no duda en cambiarse de camiseta delante de su cuñada minutos después de conocerla, come con la boca abierta y chupándose los dedos, y bebe cerveza haciendo numerosos ruidos.

Su vida se ve alterada cuando Blanche llega a su apartamento para pasar una temporada. Desde el principio, su relación con ella es tensa porque odia que actúe como si aún viviera en Belle Rêve -la plantación familiar de los DuBois-, que se crea superior y lo desprecie por su condición social. Además, considera que posee unas cualidades que no soporta en una mu- 
jer, como la presunción, la hipocresía y la superficialidad. Él la provoca para que explique qué pasó en realidad con Belle Rêve, pues sabe que oculta la verdad. Como se guía por el Código Napoleónico del Estado de Louisiana -que establece que todo lo que es de la mujer pertenece también al marido, y viceversa-, cuando se entera de la pérdida de la plantación por las deudas siente que Blanche ha engañado a Stella y que, en consecuencia, lo ha estafado a él. La aversión que tiene hacia la protagonista afecta a su mujer, con la que mantiene una relación matrimonial marcada por el deseo y la dominación. Además, incluso la agrede físicamente tras la partida de póker. Esta escena resulta muy significativa, pues Stella se refugia en casa de una vecina, y él, al darse cuenta de lo que ha hecho, rompe a llorar y la llama abatido implorando su perdón; una actitud totalmente opuesta a su conducta habitual. Ella accede a sus súplicas y hacen el amor ante el desconcierto de Blanche. Por otra parte, el vínculo que tiene con sus amigos es homosocial, sobre todo con Mitch, que también es su compañero de trabajo.

El pensamiento de Stanley es práctico y realista porque es consciente de su presente, mira al futuro con optimismo y, a diferencia de su cuñada, la vuelta al pasado no le interesa. Esta filosofía se aplica también a su ámbito sentimental, pues desea crear una familia sin la influencia de Blanche, y, por ello, convence a Stella de que debe irse para poder recuperar la normalidad matrimonial. En realidad, lo que teme es perder su rol patriarcal: "si los hombres deben afirmar su condición es posible que ésta signifique algo para ellos, probablemente porque tiene un valor social destacable que facilita la adquisición de un poder o dominación, de un estatus social privilegiado" (Sanfélix Albelda y Téllez Infantes, 2014: 374). Stanley sufre una evolución personal cuando interna a Blanche en un psiquiátrico, y Stella, arrepentida por haber permitido su plan, se va de casa con el niño que acaban de tener. Así, el ansia por perder de vista a la protagonista se cumple, pero el precio que paga por ello es la pérdida de la familia que tanto deseaba tener. Este personaje tiene un nivel socio-económico bajo, tanto por su origen como por su trabajo, pero cuenta con ingresos para sacar a los suyos adelante. Asimismo, posee un grado cultural deficiente y no muestra interés por cultivar el intelecto. A nivel sexual, es heterosexual, disfruta de su condición y recurre al sexo para someter a su mujer y a Blanche.

En cuanto al análisis como rol, hay que precisar que "lo primero que mueve a un personaje es el deseo y después la motivación, aquello que provoca que el personaje quiera alcanzar su deseo" (Galán Fajardo, 2007), y así se produce en este caso. Stanley ejerce el rol de macho dominante, pues emplea la fuerza para revalidar su poder hacia los demás, principalmente ante los personajes femeninos. Con Stella es inflexible y acalla sus protestas mediante una mezcla de autoritarismo y persuasión, pues sabe cómo manipularla. Esta conducta se agrava con Blanche, a la que amenaza e insulta porque no la soporta. Así, motivado por perderla de vista definitivamente, no duda en exterminarla de la forma más cruel posible, la violación, y, posteriormente, la lleva a un sanatorio mental porque nadie cree su versión de los hechos, ni siquiera Stella.

\subsubsection{Hal Carter: el despertar del deseo}

El forastero de Picnic altera la existencia de los vecinos de un pequeño pueblo de Kansas durante la Fiesta del Trabajo, especialmente la de las mujeres. Hal Carter es un atractivo joven sin oficio y con un espíritu soñador que despierta tanto pasiones como recelos. Tras su aparente seguridad oculta un pasado trágico, y aunque pretende empezar una vida respetable, se topa con la barrera de la incomprensión social. La acción se desarrolla prácticamente en un único 
día que será crucial para la evolución vital de todos los personajes.

A nivel iconográfico, $\mathrm{Hal}$ parece un chico de unos 25 años pero, aunque tiene más, no confiesa su edad. Destaca por un atractivo físico de carácter varonil, una complexión fornida que confirma su pasado como jugador de rugby, una sonrisa seductora y unos pequeños ojos azules de mirada sincera. Su aspecto llama la atención porque resulta viril a la par que juvenil, y se refuerza con el vestuario, como ocurre cuando llega al pueblo donde se desarrolla la acción. Él se baja de un tren de mercancías, sucio, y lleva la ropa con la que pasa buena parte de la trama: un pantalón chino beis y una camisa azul remangada a la altura de sus bíceps. Esta imagen desaliñada le otorga un aspecto sugerente, sobre todo, cuando a continuación aparece con el torso desnudo lavándose en una cascada. Resulta curioso que aparezca así en numerosas escenas, incluso sudado delante de varios personajes femeninos, quitándose el bañador en el vestuario -donde se tapa con una pequeña toalla-, o con la camisa rasgada, y esto supuso un gran impacto al potenciarse bastante su cuerpo. Asimismo, lleva también una cazadora de piel marrón, y para asistir a la fiesta del campo le prestan un estrecho traje de verano de ese color, una camisa informal y una corbata. En cuanto a su forma de hablar, se expresa con seguridad mediante un discurso ampuloso con el que pretende cautivar a los demás. Su estilo se mantiene hasta el final, así que su principal transformación ocurre cuando logra emplear un tono sereno y un discurso sin artificio para confesar su pasado.

Desde un punto de vista psicológico, Hal tiene un carácter enérgico que actúa de coraza ante su personalidad frágil. Es presuntuoso, arrogante, vividor, vago, despreocupado, pero, a la vez, es simpático y muy natural. Además, posee una desarrollada faceta de seductor y tiende a flirtear con todas las mujeres que conoce, sin importar la edad, desde las adolescentes a las madres de familia. Como admite con humor que sus debilidades son la bebida y las mujeres, se puede afirmar que es un fanfarrón. Este comportamiento insolente se debe en buena medida a que no ha recibido una educación esmerada y se ha criado en un entorno hostil, y, por ello, carece de buenos modales. Su vida es errante porque no posee ni oficio ni beneficio, y aunque parece bastante dispuesto a buscar trabajo, en realidad tiene muchas ínfulas. De todas formas, declara que desea trabajar en la fábrica de cereales del padre de su amigo Alan Benson -un chico adinerado, educado y muy formal-, y por este motivo se traslada un día de septiembre a la población de Kansas donde residen, aunque allí se va a celebrar durante esa jornada la Fiesta del Trabajo. Entre otras ocupaciones, asegura que ha trabajado en una gasolinera, en un rancho de Nevada, como modelo artístico posando desnudo, y hasta ha probado suerte en Hollywood.

Hal es muy accesible en el trato con los demás. Las personas con quienes se muestra más cercano son Madge Owens y Alan. A la primera la conoce cuando llega al pueblo, y entre ambos se produce una atracción que deben disimular porque ella está saliendo con el joven Benson, pero sin estar enamorada. Sólo a Madge consigue confesar los episodios más delicados de su pasado, como que con 14 años estuvo en un reformatorio por robar una motocicleta -y que lo hizo para huir de donde vivía-, que su madre prefería que estuviera allí recluido porque era incorregible, y que su padre estaba alcoholizado. Por su parte, con Alan mantiene una relación de amistad desde los años de Universidad que se trunca a causa de los celos de éste por su novia. Con los demás personajes, sobre todo los femeninos, se relaciona según la amabilidad que le manifiestan. Así, con la madre de Madge establece una barrera porque desprecia su 
falta de modales; con Millie Owens se siente a gusto porque comparte su naturalidad; de la maestra Rosemary se aleja cuando intenta seducirlo con descaro; y con Mrs. Potts -que es la primera que lo acoge-, construye un vínculo familiar.

El pensamiento del protagonista es soñador, y así se manifiesta cuando habla con brío de sus aventuras y de sus proyectos, pues nada parece muy creíble. Esta idea es extensible al ámbito de los sentimientos, como se constata cuando se refiere a sus idilios, pero esta actitud cambia al enamorarse. A pesar de su fama, toma distancia al percibir lo que siente por Madge -de hecho, es ella la que lo besa primero-, pero, después, se declara. Él sufre una gran evolución tras pasar casi toda la noche con la chica, lejos de la fiesta, en el coche que le ha dejado Alan, y durante ese tiempo descubre que necesita una vida estable. Cuando de madrugada va a casa de Alan a devolverle el vehículo, éste, muy enfadado, lo denuncia por robo, y Hal ataca a los agentes, roba el coche y se convierte en un fugitivo. Sin embargo, antes de fugarse a Tulsa, Oklahoma, en un tren de mercancías -como el que lo llevó hasta allí-, logra ver de nuevo a Madge y, desesperado, le plantea iniciar una vida juntos. Lo que desconoce al despedirse es que ella va a seguir sus pasos. Aunque su nivel socioeconómico es bajo, este personaje posee un nivel cultural medio porque jugando al rugby consiguió una beca para ir a la Universidad. Se trata de un joven heterosexual que sabe cómo despertar el deseo y satisfacer sus pasiones.

En cuanto al análisis como rol, ejerce el de fugitivo, tanto de forma física como psicológica. Hal pasa la vida huyendo de un sitio a otro sin poder posarse para llevar un orden, y esto indica que en realidad huye de sí mismo, pues no acepta su pasado, está acomplejado y se siente fracasado. Su mala reputación no le ayuda y tampoco sabe cómo evitar meterse en líos. Así, motivado por cambiar de vida tras enamorarse de Madge, huye a Tulsa con el anhelo de esperarla.

\subsubsection{Brick Pollit: el héroe atormentado}

El protagonista de La gata sobre el tejado de zinc es una ex estrella del rugby que padece una grave lucha interna. Brick Pollit tiene una pierna escayolada, la misma en la que tuvo la lesión que acabó con su carrera, tras caerse saltando unas vallas de atletismo en estado de embriaguez. Esta incapacidad física refleja su bloqueo psicológico, determinado por su adicción al alcohol tras la muerte de su amigo Skipper y el desdén que siente hacia su mujer, Maggie. Él es muy frágil, está hundido y carece de arrestos para seguir viviendo.

A nivel iconográfico, Brick tiene 30 años pero parece más joven por su rostro aniñado, casi imberbe, y su estilizada figura, heredera de su pasado deportivo. El protagonista sobresale por su belleza apolínea, como indican su pelo rubio cortado de forma clásica, una penetrante mirada azul, una sonrisa perfecta, y un cuerpo bien definido. Esta atractiva apariencia queda patente en la primera escena de la película, en la que aparece en las pistas del East Mississippi High School Athletic Field con un traje gris claro informal, una camisa blanca, una corbata a tono $y$ unos zapatos marrones a juego con el cinturón; sin duda, una elegante indumentaria que manifiesta que pertenece a una familia acomodada. Sin embargo, pasa casi todo el tiempo con un sobrio pijama gris oscuro y con la pierna derecha escayolada debido al reposo que tiene que mantener por la rotura de tobillo que sufre en esa escena. En cuanto a su habla, emplea con Maggie y con su padre, Big Daddy, un tono de voz muy irónico e hiriente y un discurso agresivo, mientras que con su madre, Big Mama, su hermano Gooper y su cuñada Mae suele ser parco en palabras e impasible. Él experimenta una sensible transformación tras comunicar a su 
progenitor el trágico destino que le acecha, pues, empapado por la lluvia, sube a su habitación para abandonar el pijama por un pantalón de pana marrón -que oculta la escayola-, y una camisa blanca. Esta vuelta a la ropa de calle denota su disposición por salir adelante. Además, tras encontrarse a sí mismo logra apaciguar el tono de su alocución.

Desde un punto de vista psicológico, Brick posee un carácter débil que explica su incapacidad para salir adelante. A simple vista, tiene todo en la vida para ser feliz: juventud, belleza, talento, dinero y el amor incondicional de Maggie, pero, no obstante, está sumido en una profunda depresión. Él añora sus pasados triunfos en el rugby y no le gusta su trabajo actual como locutor deportivo, pues supone comentar lo que ya no puede hacer en el campo. Asimismo, acaba de perder a su mejor amigo, Skipper, quien además era su compañero de deporte, y, como intuye su esposa, este es el motivo que lo ha llevado a beber. El chico se tiró por la ventana de la habitación del hotel que ocupaba en Chicago tras una conversación telefónica que tuvo con él, debido a un partido que perdió en esa ciudad y que Brick no jugó porque estaba hospitalizado. La culpabilidad que siente desde esta tragedia se une a la creencia de que Maggie lo intentó seducir en el citado hotel, y al descubrimiento de que no sabe si le molesta más que la supuesta infidelidad la cometiera ella o Skipper. Por ello, la desprecia, aunque es consciente de que el suicidio responde a los sentimientos que su amigo tenía por él. Con este cóctel emocional, pasa la convalecencia del tobillo con un vaso de whisky en la mano, tumbado en el sofá que hay junto al mueble bar del dormitorio que ocupa con Maggie en la casa de sus padres.

En lo que respecta a las relaciones personales, Brick se muestra más agresivo con quienes más quiere: su mujer y su padre. El vínculo que tiene con ella está marcado por el odio y la repugnancia a raíz de lo sucedido, y desde entonces se niega a que mantengan relaciones sexuales; una decisión que daña a la pareja notablemente. Aunque Maggie está desesperada por salvar la situación, él sólo sale de su apatía cuando ella menciona a Skipper, pues escuchar su nombre le produce un inmenso dolor. Mientras que el vínculo que tiene con su madre y con Gooper es cordial, su relación con Big Daddy es complicada y está llena de rencor. Brick siempre quiso tener un padre que le diera amor y no dinero, y así se lo recrimina en la dura conversación que entablan en el sótano. Como Maggie, el patriarca también percibe cuál es su verdadero problema.

El pensamiento del protagonista es íntegro, a pesar de que actúa con Maggie de una forma injusta. Esta cualidad está íntimamente ligada a sus sentimientos, aunque se halle en una encrucijada entre el amor que profesa a su esposa, el sufrimiento por la pérdida de Skipper y la profunda pasión que siente por éste, Asimismo, quiere mucho a su padre pero es incapaz de perdonar que nunca le haya mostrado afecto. El momento más tenso entre ambos se produce cuando el patriarca le habla de su difunto amigo, y él, colérico, le espeta que el cáncer que padece es terminal. Sin duda, se trata de una confesión intempestiva de la que se arrepiente mucho por el daño que le ocasiona. El reconocimiento de su culpa sobre Skipper y su posterior acercamiento a Big Daddy marcan la notable evolución que experimenta. Él pasa de una profunda apatía a la aceptación de su realidad, y decide reconciliarse con su progenitor y apostar por la vida junto a Maggie. Por ello, confirma ante todos su embarazo ficticio -para sorpresa de ésta-, y, a continuación, se reúne con ella en la habitación con la idea de hacer realidad el anuncio y enfrentarse a la vida adulta (Barton Palmer y Bray, 2009). 
Él posee un nivel socioeconómico y cultural alto por su carrera deportiva y la fortuna de su padre, pero esto no lo deslumbra. A nivel sexual, es homosexual pero no se da cuenta de su verdadera orientación hasta que fallece Skipper y comprende que estaban enamorados. Esto lo perturba y lo lleva a replantearse su sexualidad y el concepto de masculinidad, que implica "no ser femenino, no ser homosexual; no ser dócil, dependiente o sumiso; no ser afeminado en el aspecto físico o por los gestos; no mantener relaciones sexuales o demasiado íntimas con otros hombres; y, finalmente, no ser impotente con las mujeres" (Badinter, 1993: 143). A este respecto, sufre una dicotomía entre lo que siente y lo que cree que debe sentir por la educación patriarcal que ha recibido.

En cuanto al análisis como rol, Brick ocupa el de alma a la deriva. El joven está hundido en una depresión, ha perdido el interés por todo y sólo halla refugio en la evasión que le brinda el whisky. A pesar de encontrarse a las puertas de la muerte, Big Daddy se convierte en la figura clave de su recuperación. Motivado por las lecciones de vida que le ofrece, decide asumir el complejo reto de mirar hacia adelante, abandonar la bebida e intentar salir de su propio infierno.

\subsubsection{Bud Stamper: la vida interrumpida}

El protagonista de Esplendor en la hierba es un joven con ilusión y ganas de vivir que lo pierde todo de forma rápida y trágica. Bud Stamper es muy popular en el pequeño pueblo de Kansas donde vive, y así lo indican tanto su atractivo físico y personal como la elevada posición que ostenta debido a los negocios de su padre. Además, sale con Deanie Loomis, una de las chicas más formales por su belleza, candidez, educación y familia. Sin embargo, las devastadoras consecuencias del Crack de 1929 se cruzan en su vida y cambian su destino.

A nivel iconográfico, Bud sólo tiene 18 años y presenta un aspecto físico muy acorde a su edad. Es alto, tiene un cuerpo atlético que responde a su faceta de jugador de fútbol americano, $y$, además, posee un rostro muy agraciado que le proporciona un enorme éxito entre las chicas. Este atractivo se refuerza en el variado vestuario que suele utilizar en su día a día, compuesto por americanas informales, pantalones, camisas, jerséis, trajes y ropa de deporte, y análogo a su buena posición. La escena en la que su cuerpo aparece más potenciado es la del momento en el que se está duchando con sus compañeros tras uno de los partidos que juegan. Aunque es breve, resulta bastante significativa porque, hasta la fecha, el cine no había mostrado a tantos chicos juntos realizando una tarea tan íntima como es la ducha. Sin duda, refleja un interés por fomentar el atractivo físico masculino y la flexibilización de las normas del Código Hays. En cuanto a sus habilidades comunicativas, es parco en palabras y suele emplear un tono de voz pausado que sólo altera cuando se desespera, como le ocurre al percibir que no puede controlar los graves arrebatos de Deanie. La principal transformación que experimenta sucede en la parte final, cuando se arruina por el crack bursátil. A partir de entonces, presenta una ajada estética al ponerse un mono similar al de los obreros que durante años trabajaron para su familia.

Desde un punto de vista psicológico, Bud tiene un carácter honesto y un gran sentido de la responsabilidad. Su vida gira en torno a las clases en el instituto, su noviazgo, y los partidos de fútbol y de baloncesto, pero tras esta rutina oculta un dilema entre lo que le gusta y lo que debe hacer para no defraudar a su padre. A él no le hace ilusión estudiar en Yale, como éste pretende, pero le cuesta imponer su voluntad y explicarle que lo que desea es casarse cuanto antes con su novia y formarse como agrónomo para después trabajar en el negocio familiar. 
Mr. Stamper se dedica a la explotación petrolífera y tiene una gran fortuna, así que le quita la idea de la cabeza prometiéndole que cuando acabe sus estudios universitarios le dará un empleo y accederá a que se case. Sin duda, "la sencilla historia de Inge es la de la lucha entre lo justo, lo injusto y el desprestigio social, y los aspectos prácticos de la vida, y lo que resulta más conveniente para la propiedad y la familia" (Kazan, 1990: 674).

Bud destaca por su popularidad y la admiración que despierta entre los demás jóvenes de su edad, pero es en sus relaciones personales donde se observa mejor su dramatismo. Con Deanie establece una relación sentimental basada en el amor y en el respeto, que termina truncándose debido a los temores de ella -que sufre una gran inestabilidad emocional-, y a las presiones internas de él. Por otra parte, como el patriarcado y el capitalismo conforman la personalidad de su progenitor, las relaciones entre ambos son difíciles. Además, él encarna un modelo de masculinidad diferente al de éste, quien actúa de forma patriarcal para afianzar su estatus ante los demás: "sus "logros" en la vida no tienen que ver con la parte emocional, ni con sus relaciones personales, sino más bien con aquello conseguido y demostrado, material o simbólicamente en el espacio público" (Sanfélix Albelda y Téllez Infantes, 2014: 387-388). Asimismo, con su única hermana, Ginny, que es mayor que él, establece un vínculo protector, pues su carácter alocado, pero sobre todo libre, avergüenza al patriarca.

El pensamiento del protagonista es íntegro, como expresa su firme convicción de llevar un noviazgo casto con Deanie, aunque le cuesta reprimir sus deseos. De esta manera, el amor y el compromiso son los conceptos que mejor definen sus sentimientos, pero el desarrollo de los acontecimientos termina provocando una separación en la pareja que alcanza su momento más dramático cuando ella tiene que ser ingresada en un manicomio. Como "no es posible hablar del personaje sin convocar un requisito indispensable: el de la modificación" (Galán Fajardo, 2007), resulta necesario destacar la evolución vital que sufre Bud. Así se percibe dos años después, cuando Deanie, ya curada, sale del psiquiátrico y va a verlo al lugar donde ahora vive, un rancho que se halla en las antípodas de la casa donde se crió. Allí, "descubre que está casado y lleva una vida que queda muy por debajo de las aspiraciones que su padre había proyectado en él, con una mujer vulgar que está empezando a criar a sus hijos" (Kazan, 1990: 674). Al final, y debido a la Depresión, Bud consigue liberarse llevando una vida digna de granjero y fundando una familia muy distinta a la suya, pero quizá más unida y, sobre todo, nada determinada por los convencionalismos sociales. Él ostenta un nivel socio-económico alto por la estirpe a la que pertenece, pero un estatus cultural medio porque, como no quiso continuar la carrera, sólo finalizó los cursos previos a la Universidad. Se trata de un joven heterosexual que tiene una visión del sexo conservadora. Así lo manifiesta cuando disfruta de varias aventuras con otras chicas para poder respetar la virginidad de su novia.

En cuanto al análisis como rol, Bud ocupa el de antihéroe porque tiene todo para triunfar y logra una amarga victoria. Motivado por la pérdida de Deanie, su fracaso en Yale y el suicidio de su padre tras arruinarse, inicia una nueva vida en el antiguo rancho familiar, que, aunque es totalmente opuesta a la esperada, responde a lo que siempre quiso: la agricultura. No obstante, como confiesa a la protagonista al final, prefiere no preguntarse demasiado si ahora es feliz. 
DURAN MANSO, VALERIANO: La ruptura del modelo de masculinidad en el Hollywood clásico: los personajes de Tennessee Williams y de William Inge

Gráfico 1: Cuadro comparativo de personajes como persona y como rol

\begin{tabular}{|c|c|c|c|c|}
\hline & Stanley Kowalski & Hal Carter & Brick Pollit & Bud Stamper \\
\hline \multicolumn{5}{|l|}{ Iconografía } \\
\hline Edad & $28-30$ años & 25 años & 30 años & 18 años \\
\hline Apariencia física & Belleza viril & $\begin{array}{l}\text { Atractivo y } \\
\text { fornido }\end{array}$ & Belleza apolínea & Atractivo juvenil \\
\hline Vestimenta & $\begin{array}{l}\text { Sencilla y ajustada. } \\
\text { Carácter obrero }\end{array}$ & Informal & $\begin{array}{l}\text { Elegante. Pijama } \\
\text { sobrio }\end{array}$ & $\begin{array}{l}\text { Formal. Informal. } \\
\text { Deportiva }\end{array}$ \\
\hline Habla & $\begin{array}{l}\text { Ambivalente. } \\
\text { Repleta de dobles } \\
\text { intenciones. } \\
\text { Persuasiva }\end{array}$ & $\begin{array}{l}\text { Segura. Discurso } \\
\text { ampuloso }\end{array}$ & $\begin{array}{l}\text { Irónica, hiriente y } \\
\text { agresiva. Parca } \\
\text { e impasible }\end{array}$ & Pausada \\
\hline Transformación & Vestuario formal & Habla sin artificio & $\begin{array}{l}\text { Ropa de calle. } \\
\text { Habla sosegada }\end{array}$ & $\begin{array}{l}\text { Estética obrera } \\
\text { (mono de trabajo) }\end{array}$ \\
\hline \multicolumn{5}{|l|}{ Psicología } \\
\hline Carácter & $\begin{array}{l}\text { Muy fuerte y } \\
\text { violento }\end{array}$ & Enérgico y frágil & Débil & Honesto \\
\hline $\begin{array}{l}\text { Relación con los } \\
\text { demás }\end{array}$ & $\begin{array}{l}\text { Tensa con } \\
\text { Blanche. } \\
\text { Deseo/ dominación } \\
\text { con Stella. } \\
\text { Homosocial con } \\
\text { sus amigos }\end{array}$ & $\begin{array}{l}\text { Muy accesible } \\
\text { Sentimental con } \\
\text { Madge } \\
\text { Amistad con Alan }\end{array}$ & $\begin{array}{l}\text { Agresiva con } \\
\text { Maggie y con Big } \\
\text { Daddy } \\
\text { Cordial con Big } \\
\text { Mama y con } \\
\text { Gooper }\end{array}$ & $\begin{array}{l}\text { Amor y respeto } \\
\text { con Deanie. } \\
\text { Difícil con su } \\
\text { padre. } \\
\text { Protectora con } \\
\text { Ginny }\end{array}$ \\
\hline Pensamiento & Práctico y realista & Soñador & Íntegro & Íntegro \\
\hline Sentimientos & $\begin{array}{l}\text { Prácticos y } \\
\text { realistas. Objetivo: } \\
\text { fundar una familia }\end{array}$ & Soñador. Seguro & $\begin{array}{l}\text { Amor. } \\
\text { Sufrimiento. } \\
\text { Pasión }\end{array}$ & $\begin{array}{l}\text { Amor y } \\
\text { compromiso }\end{array}$ \\
\hline Evolución & Pierde a Stella & $\begin{array}{l}\text { Inicia una nueva } \\
\text { vida }\end{array}$ & $\begin{array}{l}\text { Apostar por la } \\
\text { vida y ser padre }\end{array}$ & Consigue liberarse \\
\hline \multicolumn{5}{|l|}{ Sociología } \\
\hline $\begin{array}{l}\text { Nivel social- } \\
\text { económico }\end{array}$ & Bajo & Bajo & Alto & Alto \\
\hline Nivel cultural & Bajo & Medio & Alto & Medio \\
\hline \multicolumn{5}{|l|}{ Sexualidad } \\
\hline Orientación & Heterosexual & Heterosexual & Homosexual & Heterosexual \\
\hline \multicolumn{5}{|l|}{ Rol } \\
\hline $\begin{array}{l}\text { Papel que } \\
\text { desempeñan }\end{array}$ & Macho dominante & Fugitivo & Alma a la deriva & Antihéroe \\
\hline $\begin{array}{l}\text { Motivaciones/ } \\
\text { acciones }\end{array}$ & $\begin{array}{l}\text { Alejar a Blanche/ la } \\
\text { viola y la encierra } \\
\text { en un psiquiátrico }\end{array}$ & $\begin{array}{l}\text { Cambiar de vida/ } \\
\text { huye a Tulsa } \\
\text { (Madge) }\end{array}$ & $\begin{array}{l}\text { Apoyo de su } \\
\text { padre/ decide } \\
\text { salir adelante }\end{array}$ & $\begin{array}{l}\text { Desgracias } \\
\text { personales/ inicia } \\
\text { una nueva vida }\end{array}$ \\
\hline
\end{tabular}

Fuente: Elaboración propia a partir de la plantilla de análisis del Grupo Admira 


\section{CONCLUSIONES}

La adaptación cinematográfica de la obra literaria de Tennessee Williams y de William Inge presenta un interesante y oportuno documento para reflexionar sobre la evolución del cine de Hollywood en una época marcada por la censura y el ansia de aperturismo. Aunque la mayoría de sus filmes tuvieron problemas con las directrices del Código Hays para poder estrenarse, protagonizaron una necesaria lucha por la libertad temática con el propósito de conseguir un cine más adulto y comprometido. Los temas arriesgados y la profundidad interna de los personajes de estos autores, que tanto éxito habían obtenido en Broadway, provocaron una gran repercusión en el ámbito cinematográfico por su carácter innovador. En cuanto a la construcción de personajes, destacaron por proponer nuevos modelos, sobre todo masculinos, que determinaron la naturaleza física y la profundidad psicológica de buena parte de los seres de ficción de los filmes de los años cincuenta y sesenta, especialmente las de los más jóvenes.

Las películas planteadas -Un tranvía llamado deseo, Picnic, La gata sobre el tejado de zinc y Esplendor en la hierba-, influyeron en la evolución del género melodramático hacia un mayor realismo, y, además, confirmaron la tendencia de Hollywood por adaptar grandes éxitos de la literatura norteamericana actual. Se trata de cuatro títulos muy representativos del cine clásico -en concreto, del periodo posterior a la II Guerra Mundial-, cuyos protagonistas masculinos están estrechamente ligados a los actores que les dieron vida. Marlon Brando, Paul Newman y Warren Beatty eran muy jóvenes cuando los interpretaron -William Holden tenía 37 años en Picnic-, y llevaban poco tiempo dedicados al cine; de hecho, Beatty debutó como Bud Stamper. Así, se vieron encasillados en este tipo de personaje durante sus primeros años de carrera, pues justo después volvieron a encarnar a airados, inadaptados o víctimas de problemas sexuales. En este sentido, Brando destacó como el conflictivo joven de Rebelde (The Wild One, Lázló Benedek, 1954); Newman como el fracasado aspirante a actor de Dulce pájaro de juventud; y Beatty como el prostituto de lujo de señoras maduras en La primavera romana de la señora Stone. Por su parte, Holden fue el que menos potenció este tipo de personaje posteriormente, aunque ya había interpretado a dos seres de ficción clave por su atractivo y dudosa conducta: el oportunista guionista de El crepúsculo de los dioses (Sunset Boulevard, Billy Wilder, 1950) y el galán crápula de Sabrina (Sabrina, Billy Wilder, 1954).

Estas películas indican la notable presencia que Williams tuvo en el cine de la época y el afianzamiento de este modelo de masculinidad. Así se produjo en las adaptaciones de Verano y humo y Propiedad condenada, protagonizadas, respectivamente, por Laurence Harvey y por una de las promesas del cine de los sesenta, Robert Redford. En el caso de Inge, tras Esplendor en la hierba destacaron Su propio infierno y Rosas perdidas, con Beatty y Richard Beymer, en este orden, en los roles principales. La presencia de aspectos de índole generacional o sexual -tanto de carácter represivo como liberalizador-, también se asentó gracias, en buena parte, al progresivo aperturismo del Código Hays hasta que desapareció en 1967. La última etapa del cine clásico, comprendida entre 1962 y 1972, estuvo influida por el universo de ambos autores y por la pérdida de hegemonía del prototipo clásico de masculinidad ante la primacía del nuevo, que se consolidó y se extendió al cine posmoderno. Esta realidad se manifestó claramente con intérpretes como Richard Gere, en American Gigoló (American Gigolo, Paul Schrader, 1980), donde su cuerpo era mostrado "como objeto al servicio del placer" (Guarinos, 2013: 25); Tom Cruise, en Top Gun: ídolos del aire (Top Gun, Tony Scott, 1986), y posteriormente, Johnny Deep, Brad Pitt, Leonardo DiCaprio, Jude Law o Michael Fassbender, entre muchos otros. Todos ellos 
alcanzaron el éxito con papeles donde existía una estrecha relación entre el potencial físico del personaje y su naturaleza frágil o rebelde, y en esta combinación los protagonistas de Williams e Inge fueron los pioneros.

En cuanto al análisis realizado a Stanley Kowalski, Hal Carter, Brick Pollit y Bud Stamper, se puede extraer que en el de personaje cómo persona, todos son jóvenes de edades comprendidas entre los 18 y los 30 años. Además, parte de su magnetismo reside en las características iconográficas que los definen, ya que poseen belleza, atractivo y complexión atlética, y este aspecto se refuerza con un vestuario que, lejos de disimular su cuerpo como en décadas pasadas, lo realza, lo potencia, e, incluso, lo sexualiza. A este respecto, resulta llamativo que los cuatro aparezcan con el torso desnudo en algún momento de la trama, bien porque se estén cambiando rápidamente o porque se estén aseando, y que en Picnic y en Esplendor en la hierba sean numerosas las ocasiones en las que sus protagonistas salgan así. Se trata de un tratamiento muy novedoso del cuerpo masculino que nunca antes se había mostrado en la gran pantalla, y que, además de dar naturalidad, tiene una finalidad erótica que convirtió a los actores en iconos sexuales para los espectadores mediante estos personajes.

Por otra parte, el estudio psicológico revela que poseen un pasado que les atormenta, o unas condiciones personales difíciles que afectan a su carácter, a sus relaciones con los demás personajes y a su pensamiento, sentimientos y evolución. En este sentido, contienen una base dramática potente que permite que su desarrollo resulte muy creíble en el relato. La combinación entre imagen y complejidad interna se completa en el ámbito sociológico, donde hay que destacar que este prototipo aparece en distintos niveles socioeconómicos y culturales, y, sobre todo, en el sexual. Todos son heterosexuales menos Brick, que es el primer personaje homosexual que apareció en el cine de Hollywood de forma atractiva a nivel físico -y no afeminado o vinculado con la enfermedad o la marginación social-, aunque esta orientación no se mostrara de forma clara al público por motivos de censura. Sin duda, esta imagen supone una ruptura con lo establecido en el modelo clásico, pues "las representaciones sociales y mediáticas de las otredades sexuales han estado caracterizadas por la estereotipación, el silencio y la invisibilidadad" (Colina, 2011: 175). En cuanto al análisis como rol, cada personaje actúa movido por el contexto desfavorable en la que se halla, y su realidad personal es la que delimita el tipo que ejerce. No obstante, todos parten de una situación de pérdida e inestabilidad.

Como futura investigación, se plantea un posible estudio sobre la vinculación entre el modelo de masculinidad instaurado por Marlon Brando en los cincuenta y el encarnado por los actores de las vanguardias europeas de los sesenta, como Alain Delon, para conocer como coexistieron en la última etapa del cine clásico. Asimismo, sería interesante realizar un análisis sobre los mecanismos publicitarios en torno a la imagen de los actores abordados para promocionar los filmes que protagonizaron. Este trabajo permitiría profundizar en la idea del cuerpo como producto asociado a la explotación de la producción audiovisual. Por último, sería adecuado un estudio sobre la convivencia entre la clásica masculinidad y la nueva en el melodrama de los cincuenta para constatar qué tipo de personajes las representaron y cotejar la colisión entre ambas. 


\section{REFERENCIAS}

- Antón-Pacheco, Ana (2005). El teatro de los Estados Unidos. Historia y crítica. Madrid: Langre Biblioteca Paralela.

- $\quad$ Badinter, E. (1993). XY La identidad masculina. Madrid: Alianza Editorial.

- Barton Palmer, R. (1997). "Hollywood in crisis: Tennessee Williams and the evolution of the adult film", en Roudané, Matthew C. (ed.), The Cambridge Companion to Tennessee Williams, Cambridge: Cambridge University Press, pp. 204-231.

- $\quad$ Barton Palmer, R. \& Bray, R. (2009). Hollywood's Tennessee. The Williams Films and Postwar America. Austin: University of Texas Press.

- $\quad$ Black, Gregory D. (1998). Hollywood censurado. Madrid: Cambridge University Press.

- Bosworth, Patricia. (2003). Marlon Brando. Barcelona: Mondadori.

- $\quad$ Casetti, F. y Di Chio, F. (2007). Cómo analizar un film. Barcelona: Ediciones Paidós.

- Colina, C. (coord.). (2011). Arcoíris mediático. Comunicación, género y disidencia sexual. Madrid: Ediciones Fragua.

- Connelly, T. (2004). "He is as he is-and always will be: Clark Gable and the reassertion of hegemonic masculinity", en Powrie, P.; Davies, A. \& Babington, B. (ed.). The Trouble with Men. Masculinities in European and Hollywood Cinema. London: Wallflower Press, pp. 34-41.

- Cuevas, E. (2000). Elia Kazan. Madrid: Ediciones Cátedra

- Cuevas, E. (1998). "La sociedad estadounidense bajo la mirada de Elia Kazan", en Film-Historia, Vol. VIII, No 1, pp. 29-49. http://revistes.ub.edu/index.php/filmhistoria/article/ view/12355/15117

- Diez Puertas, E. (2006). Narrativa fílmica. Escribir la pantalla, pensar la imagen. Madrid: Editorial Fundamentos.

- Durán Manso, Valeriano (2011). La complejidad psicológica de los personajes de Tennessee Williams. Frame, 7, pp. 38-76. http://fama2.us.es/fco/frame/frame7/estudios/1.3.pdf

- Durán Manso, V. (2016). "La representación del deseo en el cine de Tennessee Williams: homosexualidad masculina frente al Código Hays". FEMERIS. Revista Multidisciplinar de Estudios de Género, Vol. 1, Nos. 1-2, pp. 58-73. http://e-revistas.uc3m.es/index.php/FEMERIS/article/view/3227/1912

- Feldman, C. K. (productor), \& Kazan, E. (director). (1951). Un tranvía llamado deseo [cinta cinematográfica]. Estados Unidos: Warner Bros. Pictures.

- Frome, Shelly (2001). The Actors Studio. A History. Jefferson, North Carolina, and London: Mcfarland \& Company, Inc., Publishers.

- Galán Fajardo, E. (2007). "Fundamentos básicos en la construcción del personaje para medios audiovisuales". Revista del CES Felipe II, no 7. http://www.cesfelipesegundo.com/ revista/numeros.html

- Guarinos, V. (ed.) (2013). Hombres en serie. Construcción de la masculinidad en los personajes de ficción seriada española de televisión. Madrid: Editorial Fragua.

- Inge, W., Kazan, E., \& Maguire, C. H. (productores), \& Kazan, E. (director) (1961). Esplendor en la hierba [cinta cinematográfica]. Estados Unidos: Warner Bros. Pictures.

- Kazan, E. (1990). Mi vida. Memorias de un testigo excepcional de los tiempos dorados de Broadway y Hollywood. Madrid: Ediciones Temas de Hoy.

- Kohlmar, F. (productor), \& Logan, J. (director) (1955). Picnic [cinta cinematográfica]. Estados Unidos: Columbia Pictures.

- Martínez-Expósito, A. (2009): "Normalización y Literatura Queer", en VVAA. Seminario 
Teoría Queer: de la transgresión a la transformación social, Sevilla: Centro de Estudios Andaluces, pp. 24-38. https://www.centrodeestudiosandaluces.es/datos/factoriaideas/ PN03_09.pdf

- $\quad$ Phillips, G. D. (1980). The Films of Tennessee Williams. Philadelphia: Art Alliance.

- Rader, D. (1981). "The Art of Theatre V: Tennessee Williams". The Paris Review, 81 (Fall 1981), pp. 145-185, en Devlin, A. J. (1986). Conversations with Tennessee Williams, Jackson and London: University Press of Mississippi, pp. 325-360.

- Ramos Rodríguez, M. (2007). "Cine y moda en Hollywood: décadas de los cuarenta y cincuenta". Revista Latente, No 5, pp. 183-203.

- Sanfélix Albelda, J. y Téllez Infantes, A. (2014). "Historias de hombres. Recuperando las voces de los hombres reales". Prisma social, № 13 Narraciones de masculinidad (es), pp. 370-406. http://www.isdfundacion.org/publicaciones/revista/numeros/13/secciones/tematica/pdf/t_11_historia_hombres_370-406.pdf

- Seger, L. (2000). Cómo crear personajes inolvidables. Guía práctica para el desarrollo de personajes en cine, televisión, publicidad, novelas y narraciones cortas. Barcelona: Editorial Paidós.

- $\quad$ Smith-Howard, A \& Heintzelman, G. (2005). Critical Companion to Tennessee Williams. A literary Reference to His Life and Work. New York: Checkmark Books.

- Stanislavski, Konstantin (2010). El trabajo del actor sobre sí mismo en el proceso creador de la vivencia. Barcelona: Alba Editorial.

- $\quad$ Steen, M. (1969). A Look at Tennessee Williams. New York: Hawthorn Books.

- $\quad$ Tasker, Y. (1998). "Aproximación al nuevo Hollywood", en Curran, J., Morley, D. \& Walkerdine, V. (compliladores), Estudios culturales y comunicación. Análisis, producción y consumo cultural de las políticas de identidad y el posmodernismo. Barcelona: Ediciones Paidós, pp. 323-346.

- Weingarten, L. (Productor), \& Brooks, R. (Director). (1958). La gata sobre el tejado de zinc [cinta cinematográfica]. Estados Unidos: Metro Goldwyn Mayer.

- Williams, T. (2008). Memorias. Bacelona: Ediciones B para Bruguera.

- Zurián Hernández, F.; Martínez Ávila, D.; y Gómez Prada, H. (2015). "La ficción en la televisión generalista norteamericana y la representación de (nuevas) masculinidades". Área Abierta, Vol. 15, No 1, 53-62. https://revistas.ucm.es/index.php/ARAB/article/ view/47609/45390

- Zurián Hernández, F. y Herrero Jiménez, B. (2014). "Los estudios de género y la teoría fílmica feminista como marco teórico y metodológico para la investigación en cultura audiovisual". Área Abierta, Vol. 14, No 3, pp. 5-21. http://revistas.ucm.es/index.php/ARAB/ article/view/46357/44209

\section{CURRICULUM VITAE. VALERIANO DURÁN MANSO}

Valeriano Durán Manso es profesor contratado Doctor en el Departamento de Marketing y Comunicación de la Universidad de Cádiz, Doctor por la Universidad de Sevilla y Licenciado en Periodismo por la misma Universidad. Es investigador del Grupo de Investigación en Análisis de Medios, Imágenes y Relatos Audiovisuales (ADMIRA) del Departamento de Comunicación Audiovisual y Publicidad de la Universidad de Sevilla. Sus líneas de investigación se articulan en torno a las adaptaciones cinematográficas de Tennessee Williams, la construcción y el análisis del personaje audiovisual, el cine clásico, la historia del cine español, y el cine como reflejo de la historia de la educación. 